\title{
Diagnostics as Prevention - A Rapid Testing-Based Strategy of Sex Workers against Sexual HIV Exposure
}

\author{
Andreas Hahn ${ }^{1}$, Rebecca Hinz ${ }^{2}$, Thomas Meyer ${ }^{3}$, Ulrike Loderstädt ${ }^{4}$, Ottmar Herchenröder ${ }^{5}$, \\ Christian G. Meyer ${ }^{6,7}$, Norbert Georg Schwarz ${ }^{8}$ and Hagen Frickmann ${ }^{2,9 *}$ \\ ${ }^{1}$ Institute for Microbiology, Charité - University Medicine Berlin, Berlin, Germany \\ ${ }^{2}$ Department of Microbiology and Hospital Hygiene, Bundeswehr Hospital Hamburg, Hamburg, Germany \\ ${ }^{3}$ Institute for Medical Microbiology, Virology and Hygiene, University Medical Center Hamburg-Eppendorf, Hamburg, Germany \\ ${ }^{4}$ Institute for Hygiene and Environment, City of Hamburg, Hamburg, Germany \\ ${ }^{5}$ Institute for Experimental Gene Therapy and Cancer Research, University Medicine Rostock, Rostock, Germany \\ ${ }^{6}$ Duy Tan University, Đà Nã̃ng, Vietnam \\ ${ }^{7}$ Institute for Tropical Medicine, Eberhard Karls University, Tübingen, Germany \\ ${ }^{8}$ Infectious Disease Epidemiology, Bernhard Nocht Institute for Tropical Medicine Hamburg, Hamburg, Germany \\ ${ }^{9}$ Institute for Medical Microbiology, Virology and Hygiene, University Medicine Rostock, Rostock, Germany
}

Received: 23 March 2018; accepted: 06 April 2018

\begin{abstract}
Introduction: German sex workers have illegally established a prevention strategy, which consists of testing potential sexual partners with human immunodeficiency virus (HIV)-specific rapid diagnostic tests (RDTs) prior to engaging in unprotected sexual intercourse eventually performed in case of a negative test result. Based on a recently established modeling approach, the effectiveness of this strategy regarding the risk of HIV exposure was compared with protection provided by condom use.

Methods: Based on a literature search, the following assumptions were used for the calculations: an averaged $80 \%$ exposure risk reduction with a condom used during sexual intercourse, usage of a well-characterized 4th-generation HIV RDT, and a 10 day post-infection period without any measurable viral load in peripheral blood followed by a seroconversion period of about 3 weeks with $12.3 \%$ test sensitivity (antigen-specific) and only afterwards 97.3\% (antibodyspecific) test sensitivity.

Results: In most constellations, the HIV exposure risk in case of RDT-based prevention was lower than with condom use. Conclusions: The RDT-based HIV exposure prevention as established by sex workers is effective in most situations. A notable weakness of the strategy is the RDTs' poor sensitivity in spite of a high transmission risk during the seroconversion stage.
\end{abstract}

Keywords: HIV, rapid testing, exposure risk, prevention, sex worker, risk assessment

\section{Introduction}

Recently, we have introduced a mathematical model for the comparison of prevention strategies against sexual transmission of the human immunodeficiency virus (HIV) [1] with a focus also on exposition prevention. Although condom use is the recommended procedure to prevent an HIV infection during risky sexual contacts, a Cochrane review [2] has estimated the effectiveness of condoms in reducing HIV transmission by $80 \%$ in heterosexual settings. However, the $95 \%$ confidence interval ranged from $35.4 \%$ to $94.2 \%$ [2] and more recent studies suggest a slightly lower protection [3] than the Cochrane analysis [2]. Furthermore, condom use of men having sex with men (MSM) is not represented [2], and studies assessing condom effectiveness are affected by numerous sources of bias [4-8]. In spite of these limitations, an estimated protection rate of $80 \%$ can be considered as widely accepted and was therefore used for further calculations. However, the main limitation is not technical failure of condom use, but rather its lacking acceptance in high-risk groups as extensively discussed elsewhere [1,9].

In Germany, sex workers have illegally invented a strategy to protect themselves from exposure to HIV while avoiding condom

*Corresponding author: Department of Microbiology and Hospital Hygiene, Bundeswehr Hospital Hamburg, Bernhard Nocht street 74, D-20359 Hamburg, Germany; E-mail: Frickmann@bni-hamburg.de use, which is rather unpopular or even rejected by many of their clients. In detail, some sex workers offer unprotected intercourse if the client agrees to perform an HIV-1/2 rapid diagnostic test (RDT). This is discretely offered by a proportion of sex workers in Germany who expect higher wages when offering condom-free sex, which is forbidden in Germany in commercial sexual contacts (§32, sex worker protection law; Prostitutionsschutzgesetz). Further, it is not allowed to deliver HIV tests to private persons ( $\$ 11$, medical products law; Medizinproduktegesetz). As this approach is illegal and largely restricted either to the demimonde or private hedonistic parties, systematic scientific assessment of its effects and long-term consequences for both, the sex workers and their clientele, is yet missing.

In the very early stage of HIV infection known as the seroconversion period, however, the sensitivity of immunochromatographic RDTs for HIV detection is poor [10]. In detail, by modern 4th-generation serological HIV tests, p24 as the main viral marker protein can be detected not earlier than between the second or third week after infection. After 3 weeks or more, HIV-specific antibodies usually become measurable [11]. The use of 4th-generation RDT systems can narrow the diagnostic gap but cannot completely resolve this problem. Moreover, the sensitivity of p24 antigen detection by HIV RDT systems was shown to be poor in seroconversion panels as exemplarily demonstrated in Table 1 for the well-characterized 4th-generation

This is an open-access article distributed under the terms of the Creative Commons Attribution-NonCommercial 4.0 International License (https://creativecommons.org/licenses/by-nc/4.0/), which permits unrestricted use, distribution, and reproduction in any medium for non-commercial purposes, provided the original author and source are credited, a link to the CC License is provided, and changes - if any - are indicated. 
Table 1. Performance characteristics of the "Determine HIV1/2 Ag/Ab combo test" (Alere Inc., Waltham, Massachusetts, USA) as assessed by a meta-analysis of studies comprising seroconverter panels from patients with early HIV infections [10]

\begin{tabular}{|c|c|c|}
\hline & $\begin{array}{c}\text { Sensitivity } \\
\text { (95\% confidence } \\
\text { interval; } \mathrm{CI})\end{array}$ & $\begin{array}{c}\text { Specificity } \\
\text { (95\% confidence } \\
\text { interval; } \mathrm{CI})\end{array}$ \\
\hline Pooled results & $88.5 \%(80.1 \%-93.4 \%)$ & $99.1 \%(97.3 \%-99.8 \%)$ \\
\hline p24 antigen component & $12.3 \%(1.1 \%-44.2 \%)$ & $99.7 \%(96.8 \%-100 \%)$ \\
\hline Antibody component & $97.3 \%(60.7 \%-99.9 \%)$ & $99.6 \%(99.0 \%-99.8 \%)$ \\
\hline
\end{tabular}

HIV RDT test "Determine HIV1/2 Ag/Ab combo test" (Alere Inc., Waltham, Massachusetts, USA) [10] and the successor product scored only moderately better [12].

In summary, positive reactions of HIV RDTs in case of early HIV infections are delayed by approximately 1 week compared to serological 4th-generation bench-top devices in the laboratory as demonstrated by comparing the principles using a seroconverter panel [13]. As polymerase chain reaction (PCR), in contrast, can identify viruses even 2 weeks earlier than 4th-generation bench-top devices [14] and positive HIV RDT results were demonstrated between 10 days and 19 days after the initial positive PCR results in a previous assessment [15], it is reasonable to assume that the diagnostic gap between first transmissibility as indicated by detection of viral RNA in the PCR and reliably positive HIV RDT results is approximately 3 weeks. The practical relevance of this 3 week gap on real exposure risks by sex workers who apply RDTs for HIV exposure prophylaxis instead of condom use depends on the incidence of new HIV infections in their suitors.

Here, the HIV exposure risks (ERs) in the case of RDT use and exclusion of sexual partners with a correct or false-positive test from unprotected sex as preventive strategy was compared to the ERs in the case of condom use without knowledge about the HIV status of the sexual partners in a bio-statistical model considering effects of different HIV prevalences and incidences.

\section{Methods}

Risk modeling was based on the following assumptions:

1. Sexual HIV ER can be reduced through condom use by about $80 \%$ [2].

2. Fourth-generation RDTs targeting the p24 antigen and HIV-specific antibodies are considered the gold standard. As the best described system [10], the Determine HIV1/2 $\mathrm{Ag} / \mathrm{Ab}$ combo test was the reference for this assessment.

3. Sexual ERs start at the time of first positive PCR approximately 10 days after infection. For an approximate seroconversion period of 3 weeks between the first positive PCR and positive results in antibody-based RDTs, a p24antigen-based sensitivity of $12.3 \%$ was assumed. Subsequently, an antibody-based sensitivity of $97.3 \%$ was used for the calculations [10].

4. HIV prevalence and incidence for Germany was derived from the annual report of the National Reference Center for Infectious Diseases, RKI, for 2016 [16].

Based on these assumptions and our recently published modeling approach [1], the model presented here was established as described in Results section.

Ethics. Ethical approval was not necessary in line with national laws and regulations, because the study described a mathematical model only. Neither patient data nor patientrelated materials were used.

\section{Results}

For infection risks through sexual exposure, the following factors are relevant:

- prevalence and incidence of HIV among sexual partners,

- preventive effects of precaution/protection measures, and

- frequency of sexual contacts.

Based on the literature quoted above, the following assumptions apply. Recently infected individuals are virtually not infectious in spite of viral spread in tissues during a latency period of about 10 days without any measurable viral load in the peripheral blood [17]. Thereafter, individuals become infectious in the absence of HIV-specific antibodies detectable by common RDTs. Antigens are poorly detectable by RDTs. We assumed a sensitivity of $12.3 \%$ for antigen detection. About 1 month after infection, RDT-detectable antibodies circulate in the peripheral blood. We assumed a sensitivity of $97.3 \%$ for antibody detection. A simplified visualization of the process is provided in Figure 1.

For modeling the ER with the HIV prevalence ( $\left.\operatorname{Prev}_{\mathrm{HIV}}\right)$ and the cumulative incidence $\left(\mathrm{CI}_{\mathrm{HIV}}\right)$, we distinguish relevant periods:

- incidence frequency $F_{\mathrm{dn}}$, which is not detectable by the antibody or the antigen detecting component of the test;

- incidence frequency $F_{\mathrm{Abn}}$, where the infection is not detectable by the test's antibody component, and

- incidence frequency $F_{\mathrm{Ag}}$, where the infection is detectable only by the test's antigen component, while the individual is infectious.

We define relevant frequencies:

- frequency of infected individuals who are not detectable: Freq $_{\mathrm{dn}}=\frac{F_{\mathrm{dn}} I_{\mathrm{HIV}}}{\operatorname{Prev}_{\mathrm{HIV}}}$,

- frequency, where infection is only detectable by the antigen detecting component of the test: Freq $\mathrm{Ag}_{\mathrm{Ag}}=\frac{F_{\mathrm{Ag}} I_{\mathrm{HIV}}}{\operatorname{Prev}_{\mathrm{HIV}}}$, and

- frequency, during which the infection is detectable by the antibody detecting component of the test: Freq $\mathrm{q}_{\mathrm{Ab}}=$ $\frac{\operatorname{Prev}_{\mathrm{HIV}}-\left(F_{\mathrm{Abn}}+F_{\mathrm{dn}}\right) I_{\mathrm{HIV}}}{\operatorname{Prev}_{\mathrm{HIV}}}$.

For these frequencies holds Freq $\mathrm{Ab}_{\mathrm{b}}+$ Freq $_{\mathrm{Ag}}+$ Freq $_{\mathrm{dn}}=1$.

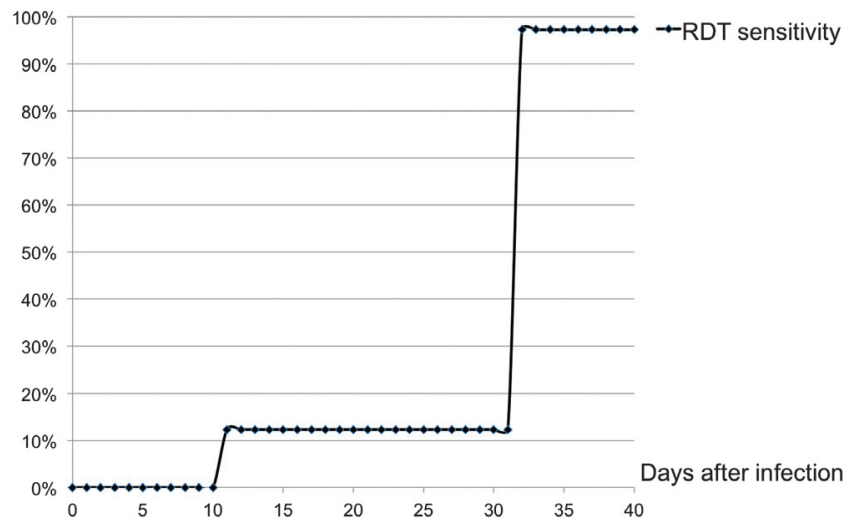

Figure 1. Simplified sensitivity of the RDT during the first 40 days of infection as used for our modeling approach. The first 10 days represent the stage without detectable viral load in the peripheral blood. Days 11 until 31 represent 3 weeks of seroconversion without measurable antibodies and only poorly detectable antigens. After day 31 , antibodies become detectable. The figure demonstrates the artificial aspect of the calculation as a continuous transition would be expected in vivo 
HIV prevalence is the basis for estimating the risk of getting in contact with HIV through a random sexual contact. ER per unprotected contact, $\mathrm{ER}_{\mathrm{U}}$ :

$$
\mathrm{ER}_{\mathrm{U}}=\operatorname{Prev}_{\mathrm{HIV}}
$$

We assume a 10 day latency $\left(d_{\text {ni }}\right)$ after a new infection, during which the newly infected individual is not infectious and there is virtually no ER. We further assume that condom use reduces the ER by around $80 \%$. To estimate the ER with condom $\left(E R_{C}\right)$, we therefore multiply the ER per unprotected contact $\left(\mathrm{ER}_{\mathrm{U}}\right)$ with $1-0.8=0.2$ :

$$
\mathrm{ER}_{\mathrm{C}}=0.2 * \mathrm{ER}_{\mathrm{U}}
$$

Here, we intend to estimate the HIV ER if an RDT is used to exclude that a partner is infected and abstains from intercourse if the test is positive, correctly or falsely. We address this ER as exposure risk per unprotected contact after testing $\left(\mathrm{ER}_{\mathrm{UT}}\right)$.

For the ER per unprotected contact after testing $\left(\mathrm{ER}_{\mathrm{UT}}\right)$, we conclude:

$$
\begin{aligned}
& \operatorname{ER}_{\mathrm{UT}}=\mathrm{ER}_{\mathrm{U}}\left(\left(1-\text { Sens }_{\mathrm{Ag}}\right) \text { Freq }_{\mathrm{Ag}}\right. \\
&\left.+\left(1-\text { Sens }_{\mathrm{Ab}}\right) \text { Freq }_{\mathrm{Ab}}+\text { Freq }_{\mathrm{dn}}\right) .
\end{aligned}
$$

ER $_{\mathrm{UT}}$ thus consists of exposure to infectious individuals who test false negative and are therefore accepted for intercourse, including exposures to infectious individuals during the period of reduced test sensitivity in the seroconversion period.

For condom use, one has to consider:

$$
\begin{aligned}
\text { ER }_{\mathrm{UT}}<E R_{\mathrm{C}} \Leftrightarrow & \left(\left(1-\text { Sens }_{\mathrm{Ag}}\right) \text { Freq }_{\mathrm{Ag}}+\left(1-\text { Sens }_{\mathrm{Ab}}\right) \text { Freq }_{\mathrm{Ab}}\right. \\
& \left.+ \text { Freq }_{\mathrm{dn}}\right)<0.2 .
\end{aligned}
$$

We assume that antibody titers remain below the detection threshold of RDT-based antibody testing for 1 month (31 days, comprising 10 days without circulating virus and about 21 days of circulating viruses without detectable antibodies) with the newly infected individual posing virtually no HIV ER to others for the first 10 days after infection. Thus, the period during which the infection is not detectable by RDTs targeting antibodies only while an ER exists and the infected individual is infectious is 21 days.

The Determine HIV1/2 Ag/Ab combo test combines antibody and antigen detection and can, in principle, detect newly acquired infections before antiviral antibodies are synthesized and detectable. Unfortunately, the sensitivity for detecting antigens in this early phase is only about $12.3 \%$.

The general risk of becoming exposed with $n$ sexual contacts (with $n$ individual exposure risks) is:

$$
\mathrm{ER}^{n}=1-\prod_{k=1}^{n}\left(1-\mathrm{ER}_{k}\right)
$$

The differential ERs per individual contact depending on prevalence and incidence of HIV in a sexually active community are shown in Figures 2-5. Notably, the dimensions of the $Y$ axis are adapted to the respective situations to allow better visibility of the relation of exposure risk to incidence and prevalence.

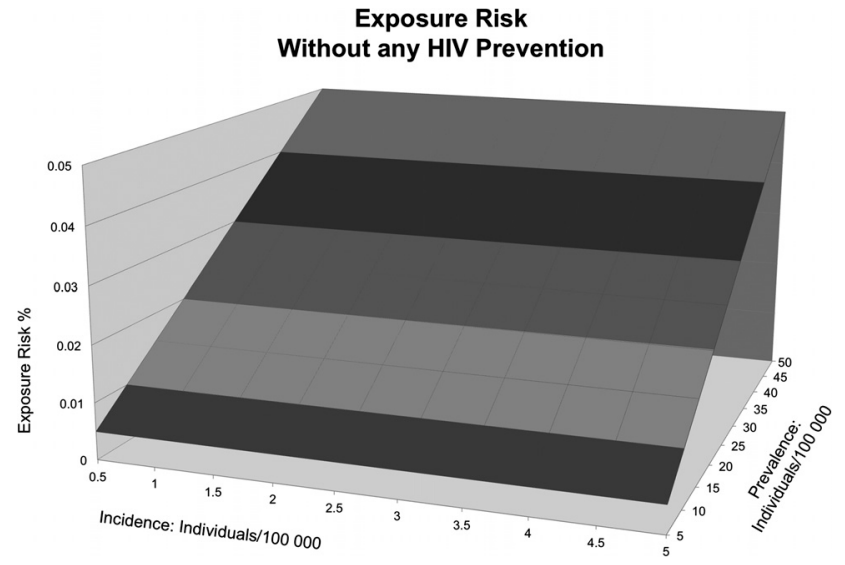

Figure 2. Exposure risk without any HIV prevention. $X$ axis: incidence per 100,000 individuals. $Y$ axis: exposure risk in percent. $Z$ axis: prevalence per 100,000 individuals

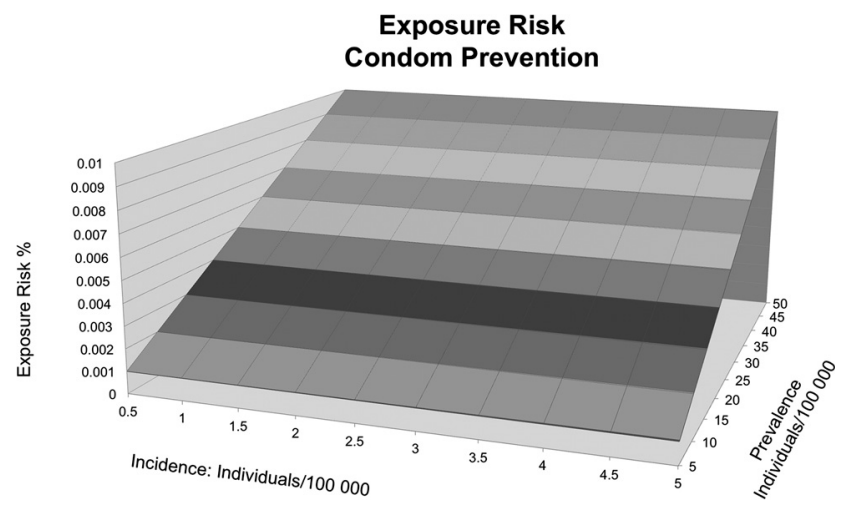

Figure 3. Exposure risk with condom-based HIV prevention. $X$ axis: incidence per 100,000 individuals. $Y$ axis: exposure risk in percent. $Z$ axis: prevalence per 100,000 individuals

\section{Exposure Risk RDT}

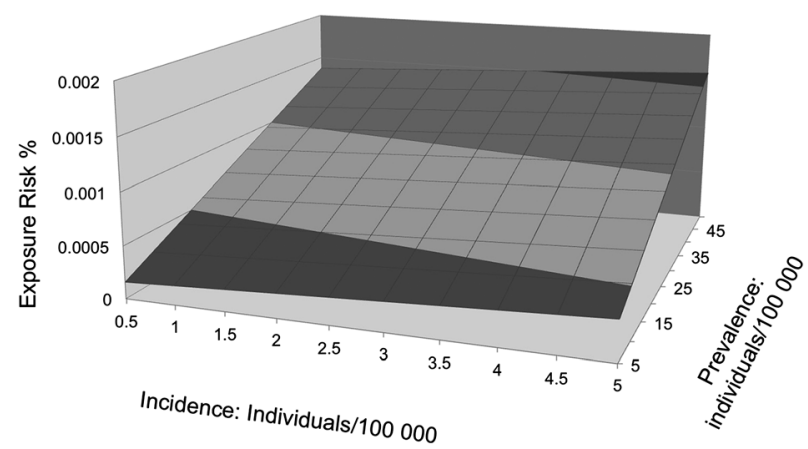

Figure 4. Exposure risk with RDT-based HIV prevention. $X$ axis: incidence per 100,000 individuals. $Y$ axis: exposure risk in percent. $Z$ axis: prevalence per 100,000 individuals

The risk of getting infected within $n$ contacts is given with:

$$
\mathrm{IR}^{n}=1-\prod_{k=1}^{n}\left(1-\mathrm{TR}_{k} \mathrm{ER}_{k}\right)
$$

where $\mathrm{TR}_{k}$ is the individual transmission risk per contact $k$.

The consequences of these mathematical assumptions are demonstrated in two examples suggesting higher exposure risks in the case of condom use than in the case of RDT-based prevention under typical circumstances. Finally, the limitations of the RDT-based approach are outlined. 


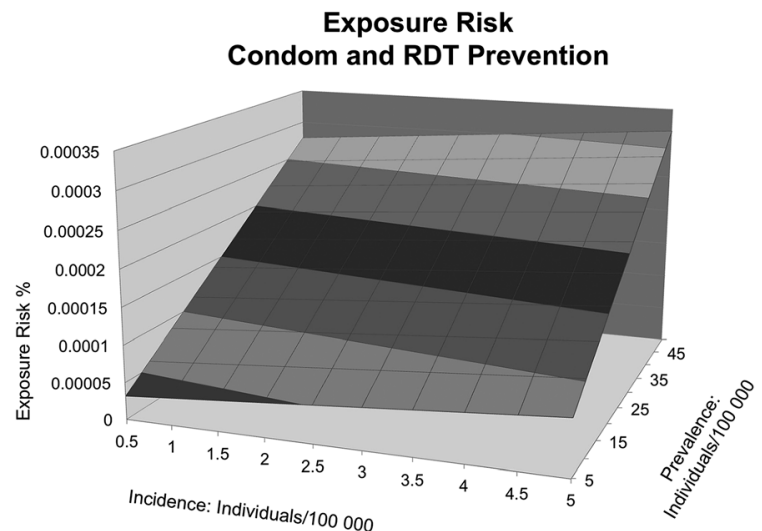

Figure 5. Exposure risk with combined condom- and RDT-based HIV prevention. $X$ axis: incidence per 100,000 individuals. $Y$ axis: exposure risk in percent. $Z$ axis: prevalence per 100,000 individuals

\section{Example 1}

With a number of 84,700 HIV-infected individuals living in Germany in 2015 and an estimated number of 3200 new infections in that same year among a population of 82.2 million as stated by Robert Koch Institute (RKI) [16], we calculate a prevalence (prev) of 0.001 and a cumulative incidence (CI) of 0.00004 . Assuming that new infections are not associated with an ER within the first 10 days and an antigen sensitivity of 0.123 and an antibody sensitivity of 0.973 , we conclude for different ERs:

$$
\begin{aligned}
\mathrm{ER}_{\mathrm{U}} & =0.001 ; \mathrm{ER}_{\mathrm{U}}{ }^{1000}=0.64 ; \mathrm{ER}_{\mathrm{C}}=0.0002 ; \mathrm{ER}_{\mathrm{C}}{ }^{1000}=0.19 \\
& \mathrm{ER}_{\mathrm{T}}=0.00003, \mathrm{ER}_{\mathrm{T}}{ }^{1000}=0.03 ; \mathrm{ER}_{\mathrm{TC}}=0.000006 ; \\
& \mathrm{ER}_{\mathrm{TC}}{ }^{1000}=0.006
\end{aligned}
$$

When ranking the ERs, the order is:

$$
\begin{aligned}
\mathrm{ER}_{\text {Unprotected }} & >\mathrm{ER}_{\text {Condom }}>\mathrm{ER}_{\text {negative Test and unprotected }} \\
& >\mathrm{ER}_{\text {negative Test and Condom }} .
\end{aligned}
$$

Table 2 summarizes the ER for the total population, heterosexuals and MSM, depending on contact frequencies and protective strategies. Condom effects in MSM contacts have to be interpreted cautiously, as the underlying meta-analysis suggesting a protection rate of $80 \%$ was focused on heterosexual contacts only [2].

\section{Example 2}

It is assumed that two sexually highly active individuals have 1000 random casual heterosexual contacts each in the same population as described in example 1. The first individual uses exclusively condoms for prevention. The second individual uses condoms in $80 \%$ of contacts. In $20 \%$, condoms are not used but a negative RDT result is mandatory.

The ER through a single contact with condom in a population with a prevalence of 0.001 and a cumulative incidence of 0.00004 is:

$$
\mathrm{ER}_{\mathrm{c}}=0.2 * 0.001=0.0002
$$

The ER through a single contact without condom, but after negative RDT in a population with a prevalence of 0.001 and a cumulative incidence of 0.00004 , is:

$$
\begin{gathered}
\mathrm{ER}_{\mathrm{UT}}=0.001 *((1-0.123) * 0.0023+(1-0.973) \\
* 0.9966+0.0011)=0.00003 .
\end{gathered}
$$

The cumulative ER after 1000 sexual contacts for the first individual is:

$$
\mathrm{ER}^{1000}=1-(1-0.0002)^{1000}=0.18 .
$$

The cumulative ER after 1000 contacts for the second individual is:

$$
\mathrm{ER}^{1000}=1-(1-0.0002)^{800}(1-0.00003)^{200}=0.15 .
$$

The higher preventive effect of the negative RDT compared to condom use causes a cumulative ER that is $16 \%$ lower in the second, compared to the first individual.

\section{Limitations of the Reliability of the RDT Approach}

Due to the low sensitivity of the RDT in very early infec-

\begin{tabular}{|c|c|c|c|c|c|}
\hline \multirow[t]{2}{*}{ Population } & \multirow[t]{2}{*}{ Number of sexual contacts } & \multicolumn{4}{|c|}{ Exposure risk (ER) in \% } \\
\hline & & Unprotected & Condom & RDT negative & RDT negative and condom \\
\hline \multirow[t]{4}{*}{ Total } & 1 & $0.1^{a}$ & 0.02 & 0.003 & 0.0006 \\
\hline & 50 & 5.0 & 1.0 & 0.15 & 0.03 \\
\hline & 100 & 9.8 & 2.0 & 0.3 & 0.06 \\
\hline & 1000 & 64.3 & 18.6 & 2.9 & 0.6 \\
\hline \multirow[t]{4}{*}{ Heterosexuals } & 1 & $0.01^{b}$ & 0.003 & 0.0004 & 0.000008 \\
\hline & 50 & 0.66 & 0.13 & 0.02 & 0.004 \\
\hline & 1000 & 12.5 & 2.7 & 0.4 & 0.08 \\
\hline & 1 & $13.5^{c}$ & 2.7 & 0.4 & 0.08 \\
\hline \multirow{3}{*}{ MSM } & 50 & 99.9 & 74.5 & 17.8 & 3.8 \\
\hline & 100 & 100 & 93.5 & 32.5 & 7.5 \\
\hline & 1000 & 100 & 100 & 98.0 & 54.3 \\
\hline
\end{tabular}
tions, it may fail as preventive strategy in risk groups with high proportions of newly infected individuals. A risk group of very high proportions of recently infected HIV-positive potential sex partners is theoretically possible, e.g., in a hedonistic club, although unlikely. Given the 3 weeks of the antigen-only stage with $12.3 \%$ RDT sensitivity only, and the later infection stages as antibody stage with $97.3 \%$ RDT

Table 2. Exposure risks depending on the frequency of sexual contacts and protective strategies for the total population as well as for heterosexual and MSM contacts 
Table 3. Estimations of average sexual HIV transmission risks in case of unprotected contacts depending on individual sexual activities and practices including risk factors beyond considering only the viral load

Average sexual HIV transmission risk per unprotected serological discordant contact [19]

\begin{tabular}{l} 
Sexual practice \\
\hline Receptive vaginal intercourse \\
Insertive vaginal intercourse \\
Receptive anal intercourse \\
Insertive anal intercourse \\
Oral intercourse \\
Risk factor \\
Male circumcision \\
Effect of rape for genocidal purposes in \\
sub-Saharan African conflict areas \\
"Dry sex," for which the vagina is dried with cloth or paper \\
or narrowed and dried by additional objects with the goal of \\
increasing friction during penetration \\
Genital mutilation in women (so-called female circumcision) \\
Concomitant STDs \\
Moderate viral load of $>2,500,000$ copies/L \\
Very early HIV infection (seroconversion)
\end{tabular}

Receptive vaginal intercourse

Insertive anal intercourse

Male circumcision

Effect of rape for genocidal purposes in

saharan African conflict areas

sensitivity, the theoretical maximum risk of exposure per sexual contact will be $87.8 \%$ in a risk group of $100 \%$ HIVpositive potential sexual partners in the antigen-only stage. This risk declines with increasing proportions of individuals in the antibody stage and increasing proportions of HIV-negative partners. In contrast to the RDT approach, the ER for condom use remains at $20 \%$, even under most unfavorable conditions.

If we assume that in this setting the frequency of infected individuals without antibodies and without detectable viral load is 0 , the underlying formula for the individual exposure risk is then simplified as follows:

$$
\mathrm{ER}_{\mathrm{UT}}=\operatorname{Prev}_{\mathrm{HIV}}\left(\left(1-\text { Sens }_{\mathrm{Ag}}\right) \text { Freq }_{\mathrm{Ag}}+\left(1-\text { Sens }_{\mathrm{Ab}}\right) \text { Freq }_{\mathrm{Ab}}\right)
$$

With the assumption depicted in the example above, namely that the frequency of potential partners without antibodies or HIV viremia is $0 \%$ and there is a sensitivity of 0.123 in the antigen-only phase as well as 0.973 in the antibodyonly phase, the consequence is that, for $E R_{U T}<E R_{C}$, a frequency of antibody-positive individuals (antigen-only positive individuals $)$ of Freq $\mathrm{Ab}_{\mathrm{b}}>0.796\left(\Rightarrow\right.$ Freq $\left._{\mathrm{Ag}}<0.204\right)$ is required. The contrary situation is described by $E R_{U T}>E R_{C}$ if Freq $_{\mathrm{Ab}}<0.796$. If, in contrast, we assume that Freq $\mathrm{Ab}_{\mathrm{B}}<$ 0.796 and Freq $\mathrm{Ag}_{\mathrm{Ag}}<0.204$, then it follows that $\left(\left(1-\right.\right.$ Sens $\left._{\mathrm{Ag}}\right)$ Freq $_{\mathrm{Ag}}+\left(1-\right.$ Sens $\left._{\mathrm{Ab}}\right)$ Freq $\left._{\mathrm{Ab}}\right)=0.2$ and therefore ER $_{\mathrm{UT}}=$ $\operatorname{ER}_{\mathrm{U}}\left(\left(1-\right.\right.$ Sens $\left._{\mathrm{Ag}}\right)$ Freq $_{\mathrm{Ag}}+\left(1-\right.$ Sens $\left._{\mathrm{Ab}}\right)$ Freq $\left._{\mathrm{Ab}}\right)=\mathrm{ER}_{\mathrm{U}} * 0.2=$ $\mathrm{ER}_{\mathrm{C}}$ describes identical ERs in RDT-only- and condom-onlybased prevention.

\section{Discussion}

In most conditions, the risk of HIV exposure per risky contact is lower with an RDT-based approach than with condom use as suggested by the presented exposure risk estimates. In contrast, condom use yields a better protection against an HIV-infection than the RDT-based approach, if considerably more than $20 \%$ of risky potential contacts involve HIV-infected individuals who are newly infected and still in the antigen-only phase. Although such a situation is rather unlikely, it may occur, e.g., if HIV is newly introduced in a very promiscuous and sexually highly active community. Unprotected sexual contact with HIV-infected individuals in the seroconversion stage is particularly dangerous because the transmission risk is increased by factor 10 to 100 compared to the baseline risk during the chronic stage of infection due to very high viral loads [18]. As this study models exposition risks and not transmission risks, respective estimations would be beyond its scope but are described in detail elsewhere [1]. As also detailed there [1], molecular RDT systems based on nucleic acid amplification (NAT) might be applied to solve the problem of lacking sensitivity in the early infection stages. Due to financial and logistic reasons, however, the application of NAT-based RDT systems for leisure purposes will be restricted to well-equipped and resource-rich hedonistic communities and appears less likely to be deployed. In addition to the effects of viral load [1], several other factors can interfere with the risk of HIV transmission in the case of unprotected sexual exposure as shown in Table 3. Furthermore, acquisition of other STDs is facilitated by a prevention strategy solely based on a system to disclose an HIV infection in an individual. A combination of a test-based strategy with condom use can further reduce HIV exposure, compared to applying either one strategy alone.

Residual protection against STD transmission can remain even in the case of broken condoms. Based on material testing of condoms and calculations of the ejaculate volume compared to condom-free sex, relative STD transmission risks were calculated as $6 \%$ in cases of condom bursts, $0.008 \%$ o $(0.8 / 100000)$ in condoms with a visible leakage, and $0.00004 \%$ o $(0.004 / 100000)$ in condoms invisibly perforated [25]. Such considerations are superfluous if the condom is totally disrupted, as this can be the case during continuous hard sexual intercourse or if the condom is deliberately omitted under the influence of drugs or alcohol $[26,27]$. Under such circumstances, decline of sexual partners who are not RDT tested may be the safer alternative.

The presented modeling approach demonstrates that preventive strategies should not basically be rejected as inefficient just because they are established within risk groups and not by prevention specialists. As recently suggested, punitive laws are likely to impede HIV prevention [28, 29]. This may also affect the here described legally banned prevention approach of sex workers in Germany.

\section{Conclusions}

In spite of the good performance of RDT-based pre-screening of potential sex partners for an HIV infection prior to unprotected sexual contacts, there remain limitations of this approach with a particular focus on the early phases of the infection and on the risk of getting infected with other STDs. 


\section{Funding Sources}

No financial support was received for this study.

\section{Authors' Contribution}

A.H. performed the mathematical modeling. A.H., R.H., T.M., U.L., O.H., C.G.M., N.G.S. and H.F. jointly performed the literature research and wrote and reviewed the manuscript. H.F. provided the concept.

\section{Conflicts of Interest}

The authors declare no conflict of interest.

\section{References}

1. Hahn A, Hinz R, Meyer T, Loderstädt U, Herchenröder O, Meyer CG, et al. HIV prevention strategies and risk of infection: a model-based analysis. Epidemiol Infect. Forthcoming 2018. Available from: https://doi.org/10.1017/ S0950268818000845.

2. Weller S, Davis K. Condom effectiveness in reducing heterosexual HIV transmission. Cochrane Database Syst Rev. 2002;CD003255.

3. Giannou FK, Tsiara CG, Nikolopoulos GK, Talias M, Benetou V, Kantzanou M, et al. Condom effectiveness in reducing heterosexual HIV transmission: a systematic review and meta-analysis of studies on HIV serodiscordant couples. Expert Rev Pharmacoecon Outcomes Res. 2016;16:489-99.

4. Vera EG, Orozco HH, Soto SS, Aburto EL. Condom effectiveness to prevent sexually transmitted diseases. Ginecol Obstet Mex. 2008;76;88-96.

5. Mindel A, Sawleshwarkar S. Condoms for sexually transmissible infection prevention: politics versus science. Sex Health. 2008:5:1-8.

6. Koss CA, Dunne EF, Warner L. A systematic review of epidemiologic studies assessing condom use and risk of syphilis. Sex Transm Dis. 2009;36:401-5.

7. Holmes KK, Levine R, Weaver M. Effectiveness of condoms in preventing sexually transmitted infections. Bull World Health Organ. 2004;82:454-61.

8. Warner L, Stone KM, Macaluso M, Buehler JW, Austin HD. Condom use and risk of gonorrhea and Chlamydia: a systematic review of design and measurement factors assessed in epidemiologic studies. Sex Transm Dis. 2012; 33:36-51

9. Joined United Nations Programme on HIV/AIDS (UNAIDS) Global Report. UNAIDS report on the global AIDS epidemic 2013. WHO Library Cataloguing-in-Publication Data 2013. Available from: http://www.unaids.org/ sites/default/files/media_asset/UNAIDS_Global_Report_2013_en_1.pdf.

10. Smallwood M, Vijh R, Nauche B, Lebouché B, Joseph L, Pant Pai N Evaluation of a rapid point of care test for detecting acute and established hiv infection, and examining the role of study quality on diagnostic accuracy: a Bayesian meta-analysis. PLoS One. 2016;11:e0149592.

11. Dewar R, Goldstein D, Maldarelli F. Diagnosis of human immunodeficiency virus infection. In: Mandell GL, Bennett JE, Dolin R, editors. Mandell, Douglas and Bennett's principles and practice of infectious diseases. 7th ed. Philadelphia, PA, USA: Churchill Livingston Elsevier; 2010. p. 1668.

12. Meyer T, Schüttler CG, Straube E, Roß RS, Stürmer M, Jansen K, et al. Schnelltest-Diagnostik sexuell übertragbarer infektionen in niedrigschwelligen Einrichtungen. Gemeinsame stellungnahme des RKI, PEI und der DSTIG. Bundesgesundheitsblatt Gesundheitsforschung Gesundheitsschutz. 2017;60: 245-54.
13. Bremer V, Brockmeyer N, Hagedorn HJ, Knoell A, Marcus U, Meyer $T$, et al. Gemeinsame stellungnahme des RKI, PEI und der DSTIG. Schnelltests in der diagnostik sexuell übertragbarer infektionen. Epi Bull. 2012;5:37-41.

14. Rabenau HF, Bannert N, Berger A, Donoso Mantke O, Eberle J, Enders $\mathrm{M}$, et al. Nachweis einer Infektion mit humanem immundefizienzvirus (HIV) serologisches screening mit nachfolgender bestätigungsdiagnostik durch antikörper-basierte testsysteme und/oder durch hiv-nukleinsäure-nachweis: stellungnahme der Gemeinsamen Diagnostikkommission der Deutschen Vereinigung zur Bekämpfung von Viruskrankheiten e. V.(DVV e. V.) und der Gesellschaft für Virologie e. V. (GfV e. V.). Bundesgesundheitsblatt Gesundheitsforschung - Gesundheitsschutz. 2015;58:877-86.

15. Scheiblauer H. Zulassung und Konformitätsbewertung von HIV-, HBV- und HCV-tests. J Dtsch Dermatol Ges. 2016;14:22-3.

16. Marcus U, an der Heiden M. Schätzung der zahl der HIV-neuinfektionen und der gesamtzahl von menschen mit HIV in Deutschland. Stand Ende 2015. Epi Bull. 2016:45:497-509.

17. Kosaka PM, Pini V, Calleja M, Tamayo J. Ultrasensitive detection of HIV-1 p24 antigen by a hybrid nanomechanical-optoplasmonic platform with potential for detecting HIV-1 at first week after infection. PLoS One. 2017;12: $\mathrm{e} 0171899$.

18. Wawer MJ, Gray RH, Sewankambo NK, Serwadda D, Li X, Laeyendecker O, et al. Rates of HIV-1 transmission per coital act, by stage of HIV-1 infection, in Rakai, Uganda. J Infect Dis. 2005;191:1403-9.

19. Audebert F, Behrens G, Bogner J, Brockmeyer N, Hammond A, Hartmann M, et al. Deutsch-Österreichische Leitlinien zur postexpositionellen Prophylaxe der HIV-Infektion. 2013. p. 2-26.

20. Arastèh K, Arendt G, Bader A, Berg T, Bitzer J, Bogner J, et al. Postexpositionelle prophylaxe der HIV-infektion. Deutsch-Österreichische Empfehlungen. Aktualisierung 2007. 2007. p. 4-42.

21. Spiegel PB, Bennedsen AR, Claass J, Bruns L, Patterson N, Yiweza D, et al. Prevalence of HIV infection in conflict-affected and displaced people in seven sub-Saharan African countries: a systematic review. Lancet. 2007;369:2187-95

22. Frickmann H, Wulff B, Loderstädt U, Hagen RM, Sturm D, Polywka S. From IEDs to AIDS? Detection of HIV in human corpses by rapid screening tests after suspected intentional transmission in terrorist attacks. J R Army Med Corps. 2013;159:278-82.

23. Low N, Chersich MF, Schmidlin K, Egger M, Francis SC, van de Wijgert $\mathrm{JH}$, et al. Intravaginal practices, bacterial vaginosis, and HIV infection in women: individual participant data meta-analysis. PLoS Med. 2011;8: e1000416.

24. Smolak A. The association of female circumcision with HIV status and sexual behavior in Mali: a multilevel analysis. J Acquir Immune Defic Syndr. 2014;65:597-602.

25. Sing A. Zur Epidemiologie von sexuell übertragbaren Erkrankungen: der Beitrag der Sozialen Netzwerk-Analyse zu einem komplexen Feld. Mikrobiologe. 2011;21:150-60.

26. Daskalopoulou M, Rodger A, Phillips AN, Sherr L, Speakman A Collins S, et al. Recreational drug use, polydrug use, and sexual behaviour in HIV-diagnosed men who have sex with men in the UK: results from the crosssectional ASTRA study. Lancet HIV. 2014;e22-31.

27. Rehm J, Shield KD, Joharchi N, Shuper PA. Alcohol consumption and the intention to engage in unprotected sex: systematic review and meta-analysis of experimental studies. Addiction. 2012;107:51-9.

28. Voelker R. Punitive laws undermine HIV prevention, says report. JAMA. 2012;308:661.

29. Global Commission on HIV and the law. Risk, rights \& health. UNDP. 2012. Available from:http:/www.hivlawcommission.org/resources/report/FinalReport-Risks, Rights\&Health-EN.pdf. 